\title{
Maize Root Architecture and Water Stress Tolerance: An Approximation from Crop Models
}

\author{
Ramiro Carretero,* Federico Esteban Bert, and Guillermo Podestá
}

\begin{abstract}
This work presents an assessment of potential advantages of drought tolerance in maize (Zea mays L.) production. A higher water uptake resulting from an enhanced root exploration at deep soil layers seems to be the most promising mechanism. The potential field-level impacts of this mechanism is assessed in two contrasting agroecological areas of the Argentine Pampas using the CERES-Maize model. The soil root growth factor parameter (SRGF) was manipulated to represent a modified maize hybrid with higher density of deep roots. Enhanced root exploration increased maize transpiration and consequently biomass production and yields. Benefits of the modified hybrid tend to be higher under low water availability conditions (low soil water content at sowing and/or rains during crop cycle). Although higher yield responses to root architecture changes were initially expected in the marginal semiarid area (Pilar), the opposite was observed: the average yield increases were 4.7 and $11.7 \%$ for Pilar and Pergamino, respectively. The modified hybrid showed lower yields than the current one in approximately $10 \%$ of the simulated situations. There were no yield penalties for the modified hybrid in cropping cycles with high water availability. This work shows strong interactions between root architecture and the environmental conditions in which crops are grown that affect potential field-level benefits. We highlight the need for assessing attributes tied to drought tolerance in the context of agroecological conditions in which plants will be grown to identify which drought-tolerance mechanisms might prove effective under different water-stress conditions.
\end{abstract}

The Argentine Pampas is one of the most important crop production regions in the world. As the majority of crop production of the Pampas is rain fed, most year-to-year changes in production depend on rainfall variability. The Pampas show strong climate variability on inter-annual to inter-decadal scales. The El Niño Southern Oscillation phenomenon (ENSO) is one of the main sources of rainfall variability at inter-annual scales (Goddard et al., 2001; Ropelewski and Halpert, 1987; Ropelewski and Halpert, 1989) explaining a significant proportion of yield variability in summer crops (Podestá et al., 1999). Furthermore, a steady increase in late spring to summer rains has been observed in the Pampas since the 1960s (Boulanger et al., 2005; Minetti et al., 2003; Rusticucci and Penalba, 2000). The increase has been particularly marked near the western margin of the Pampas, displacing westward the transition to semiarid regions that represent the boundary of rain-fed agriculture (Berbery et al., 2006). However, some reports suggest a return to

R. Carretero, Facultad de Agronomía, Universidad de Buenos AiresCONICET, Av. San Martín 4453, C1417DSE, Buenos Aires, Argentina; F.E. Bert, Facultad de Agronomía, Universidad de Buenos Aires- CONICET, Av. San Martín 4453, C1417DSE, Buenos Aires, Argentina; G. Podestá; Rosenstiel School of Marine and Atmospheric Science, University of Miami, 4600 Rickenbacker Causeway, Miami, FL 33149. Received 23 Apr. 2014.

${ }^{*}$ Corresponding author (rcarrete@agro.uba.ar).

Published in Agron. J. 106:2287-2295 (2014)

doi:10.2134/agronj14.0214

Copyright ( $\odot 2014$ by the American Society of Agronomy, 5585 Guilford Road, Madison, WI 53711. All rights reserved. No part of this periodical may be reproduced or transmitted in any form or by any means, electronic or mechanical, including photocopying, recording, or any information storage and retrieval system, without permission in writing from the publisher. drier conditions in the Pampas (Minetti et al., 2003) and recent extreme droughts (Skansi et al., 2009) have heightened stakeholders' concerns. Although much uncertainty remains regarding the projected paths of future climate, particularly on regional scales and time horizons of a few years (Boulanger et al., 2007) an eventual return to a drier epoch would increase the sensitivity of current agricultural production systems to rainfall amounts and distribution.

Historically, land use in the Pampas included a mixed crop-cattle rotation. During the last few decades, this rotation gradually gave way to continuous agriculture (Paruelo et al., 2005) and, more recently, the rotation of alternative field crops has been somewhat replaced by an increasing trend toward monoculture of soybean [Glycine max (L.) Merr.] (Delvenne et al., 2013; Leguizamón, 2014; Reboratti, 2010). Worries are growing about soybean monoculture and its possible negative impacts on the physical, chemical, biological and socioeconomic properties of production systems (Manuel-Navarrete et al., 2009). Maize is the main alternative crop to soybean in the Pampas (Calviño and Monzón, 2009). From an economic viewpoint, maize offers a diversification alternative that helps to reduce economic risks. In turn, maize provides significant amounts of organic $\mathrm{C}$ that may enhance the physical and chemical properties of soils. However, maize production is highly sensitive to water deficits during flowering, a critical stage for yield definition (Hall et al., 1992). In the Pampas,

Abbreviations: DSSAT, decision support system for agrotechnology transfer; ENSO, El Niño Southern Oscillation phenomenon; EW, extractable water; $\mathrm{EW}_{\text {in }}$, initial soil extractable water; HI, harvest index; RLD, root length distribution; SRGF, soil root growth factor; WUE, water use efficiency 
maize flowering (mid-December to early January) coincides with the beginning of austral summer, the period with maximum atmospheric water demand. The availability of maize hybrids capable of maintaining high production levels under water stress conditions would improve the physical and economic results of this crop contributing to its broader use in rotations, with associated benefits to soil structure and system sustainability. Furthermore, although high uncertainty remains about scenarios of future rainfall in the Pampas, drought-tolerant maize hybrids may help sustain current production levels if drier conditions return.

For the purpose of this study, tolerance to water stress is defined as maintenance of productivity and not just as survival (Passioura, 1996, 2012). Understood in these terms, water stress tolerance could be achieved through different ecophysiological processes: (i) increase of transpiration through higher uptake of soil water, (ii) more efficient use of transpired water (i.e., improvement of a crop's water use efficiency, WUE), or (iii) increase of the efficiency of biomass conversion into yield (i.e., the harvest index) (Passioura, 1996, 2006, 2012).

Robertson et al. (1993) and McKenzie et al. (2009) pointed out that many crops leave available water at the deepest soil layers-even when they are exposed to severe water deficit. Higher water uptake could be achieved through: (i) modification of the plant's root architecture to increase water uptake from deeper soil layers or (ii) osmotic adjustment that allows a sustained transpiration rate. Previous studies have shown that genotypes with higher water extraction from deep soil layers presented advantages under water stress conditions (Hammer et al., 2009; Jones and Zur, 1984; Jordan et al., 1983; Lorens et al., 1987a, 1987b; Salih et al., 1999; Sinclair and Muchow, 2001; Wan et al., 2000). Achieving higher root exploration of deep soil layers depends not only on increasing root depth, but also root density at deeper layers, thus allowing higher soil occupancy. In other words, root distribution in the soil should be more vertically uniform, decreasing root density at top layers and increasing it at depth. On the other hand, maize and wheat (Triticum aestivum L.) genotypes with higher osmotic adjustment ability showed greater water uptake and yields under water stress conditions (Chimenti et al., 2006; Morgan and Condon, 1986).

In addition to a higher water uptake, a more efficient use of transpired water may contribute to maintain productivity under water stress conditions. However, the genotypic variability of WUE is usually associated with reduction of water use (the denominator in the WUE formulation) rather than with an increase in biomass production (the numerator) (Blum, 2009). As shown by Rebetzke et al. (2002), WUE improvement of selected wheat lines was due to reduced water uptake during early stages of the crop cycle (i.e., a conservative use of soil water, deferring use to critical reproductive stages), mainly in sites where crops are exposed to terminal droughts and growth depends on soil water stored before sowing (Blum, $2005,2009)$. However, when genotypes used by Rebetzke et al. (2002) were tested in stressful environments without terminal droughts, no differences were observed (Condon et al., 2002). Often agricultural regions are not exposed to terminal droughts but rather to uneven rainfalls throughout the cropping cycle (e.g., the Argentine Pampas) (Passioura, 2012). As such, the best strategy for maintaining productivity under water stress conditions may be the increase of water uptake, generally associate to WUE reductions (Blum, 2005).

Finally, the harvest index (HI, the ratio of yield to aerial plant biomass) is highly dependent on the crop's partitioning of total available water between (i) pre-flowering (canopy development and potential grain number determination) and (ii) post-flowering (grain set and grain filling) stages (see Fig. 4 in Passioura, 2006). Thus, the pattern of water availability during the crop cycle can affect the HI significantly. Regardless of water distribution throughout the crop cycle, the HI may be reduced by short water stresses during specific stages, since the process of flower fertilization in maize is very sensitive to water stress, as fragile organs like pollen, stigmata, and ovaries are involved (Bruce et al., 2002). Thus, as discussed by Passioura (2006), a short water stress during a critical development stage could reduce crop yield due to induction of infertility, even with a suitable availability of water during the rest of the cropping cycle.

In summary, and in line with other studies (Hall and Richards, 2013; Ludlow and Muchow, 1990; Richards, 2006; Singh et al., 2014; Tardieu, 2012), one of the most promising attributes to enhance drought tolerance in the Pampas is increasing water uptake from deeper soil layers. There are evidences of genes affecting the root architecture of maize (Giuliani et al., 2005). Singh et al. (2010) found differences in root angle between maize hybrids, an attribute associated with root architecture (Kato et al., 2006; Manschadi et al., 2008). Recently, Nagore et al. (2014) found different soil water depletion for deeper soil layers $(80-140 \mathrm{~cm})$ among maize hybrids released in different decades in Argentina. Campos et al. (2004) observed that new hybrids appeared to have higher water extraction from deep soil layers than old hybrids. These evidences demonstrate the existence of genotypic variability in the ability to extract water from deep soil layers.

The genes involved in drought tolerance are not completely identified or publicly listed. At the same time, the physiological processes regulated by the genes involved in drought tolerance are not completely known and/or not reported. This information is important to understand under which water-stress conditions the mentioned genes might prove effective (Hall and Richards, 2013), particularly considering likely interactions between physiological processes and the environment (climate conditions and soil) (Passioura, 2012). Many studies have used crop models to assess the impacts on productivity of particular changes in eco-physiological processes or attributes (i.e., transpiration rate, root architecture, rooting depth, stomata conductance, etc.) under water-limited environments (Hammer et al., 2005, 2009; Jones and Zur, 1984; Jordan et al., 1983; Lilley and Kirkegaard, 2011; Manschadi et al., 2006; Sinclair and Muchow, 2001). To our knowledge, there are no studies evaluating how changes in eco-physiological processes or attributes linked to drought tolerance may affect maize productivity under the prevailing environmental conditions in the Argentine Pampas.

The goal of this study was to assess the potential field-level production advantages of changes in maize root architecture to enhance water uptake from deep soil layers under contrasting environmental conditions of the Pampas. To address this goal we performed simulations with the decision support system for agrotechnology transfer (DSSAT) package v3.5 (Hoogenboom 
et al., 1999) for two maize hybrids differing only in root architecture. We focused on two contrasting agro-climatic areas of the Pampas with the aim of exploring potential interactions between the modified attribute (root architecture) and the environment (soil type and rainfall levels).

\section{METHODOLOGY AND APPROACH}

\section{Maize Model and Changes in Root Architecture}

The CERES-Maize module (Jones and Kiniry, 1986) within DSSAT package v3.5 (Hoogenboom et al., 1999) has been calibrated and validated in many regions of the world, including the Argentine Pampas (Guevara et al., 1999; Mercau et al., 2001). Information required to run this model includes: (i) daily meteorological data (maximum and minimum temperature, daily precipitation, daily solar radiation); (ii) soil parameters (texture, organic matter, bulk density, etc.); (iii) genetic coefficients that describe development and growth processes for the different genotypes; (iv) crop management information (sowing date, genotype, plant density, $\mathrm{N}$ fertilization strategy, etc.); and (v) initial soil water and $\mathrm{N}$ content.

We used CERES-Maize to simulate growth and development of two maize hybrids: a current hybrid and a hypothetical one with modifications in its root exploration profile. The modified hybrid had higher root density at deep soil layers than the current hybrid. Thus, the two maize hybrids compared had the same genetic coefficients, but differed only in the distribution of roots among soil layers. Differences in root distribution profile were simulated by manipulating one of DSSAT's soil parameters- the SRGF (unitless) - that determines the aptitude of different soil layers for root growth. An SRGF value must be defined (by the user) for each soil layer. The SRGF is usually defined as a function of depth: SRGF values are higher for upper soil layers. Values used for simulations of this study were determined through an exponential function proposed by Jones et al. (1991):

$$
\mathrm{SRGF}=(1-\mathrm{ZA} / 3)^{\mathrm{WCG}}
$$

where ZA is the depth $(\mathrm{m})$ to the middle of each soil layer and WCG is a genetic coefficient. From this equation, the lower the WCG value, the more uniform the root distribution throughout the soil profile. In other words, genotypes with higher WCG values will have higher root density on upper soil layers. In this study, we set WCG to 3 for the current hybrid, whereas the corresponding value for the modified hybrid was 0 (zero).The values selected were intended to represent contrasting extremes in root distribution. A WCG of 2 was recommended by Jones et al. (1991) and used by Mercau et al. (2001) in simulations aimed at validating the CERES-Maize model in the Pampas. Further, Robertson et al. (1993) used $\mathrm{WCG}=3$ to simulate grain sorghum [Sorghum bicolor (L.) Moench.] growth. In contrast, we defined WCG $=0$ as an interesting extreme value-though not empirically based-to simulate a homogeneous root distribution (i.e., to induce a higher root density at deeper soil layers).

\section{Cases of Study and Input Data}

Simulations were performed for two sites in the Argentine Pampas with contrasting agro-ecological conditions:
Pergamino (Buenos Aires province, $33^{\circ} 56^{\prime} \mathrm{S}, 60^{\circ} 33^{\prime} \mathrm{W}$ ) and Pilar (Córdoba province, $31^{\circ} 41^{\prime} \mathrm{S}, 63^{\circ} 53^{\prime} \mathrm{W}$ ), representing near-optimal and relatively marginal agricultural conditions, respectively. Pergamino is one of the most productive subregions of the Pampas, whereas Pilar is a semiarid subregion and experiences water stresses more often. Median annual precipitation is $937 \mathrm{~mm}$ in Pergamino and $738 \mathrm{~mm}$ in Pilar (Podestá et al., 2009). In Pilar, the annual cycle of rainfall has a marked winter minimum that makes summer crops very dependent on spring rains (Ferreyra et al., 2001). Daily weather data for the period 1931 to 2006 were used in the simulations for both locations (i.e., 75 cropping cycles were simulated). We selected a representative soil series for each site: a Typic Argiudoll (Pergamino soil series) for Pergamino and an Entic Haplustoll (Oncativo soil series) for Pilar. Both soils are 2-m deep and thus having a considerable water storage capacity (300 and $292 \mathrm{~mm}$ for the Pergamino and Oncativo soil series, respectively) that often helps overcome rain shortages during the growing season. Profile parameters for both series were based on soil survey data and 1:50.000 maps provided by Argentina's National Institute of Agricultural Technology (INTA).

Genetic coefficients used for simulations correspond to the hybrid Dekalb 682 and were available from our previous research in this area (Bert et al., 2006). This hybrid has been widely used in the Pampas until recently. Crop management strategies are very similar for both sites despite their agroecological differences. Thus, a single typical maize agronomic management was defined for both sites: (i) sowing date: 27 October; (ii) plant density: 7 plants $\mathrm{m}^{-2}$; and (iii) $\mathrm{N}$ fertilization rates: $40 \mathrm{~kg} \mathrm{~N} \mathrm{ha}^{-1}$ at sowing, plus $100 \mathrm{~kg} \mathrm{~N} \mathrm{ha}^{-1}$ $25 \mathrm{~d}$ after sowing. Initial soil $\mathrm{N}$ was set to $70 \mathrm{~kg} \mathrm{ha}^{-1}$. CERESMaize does not take into account nutrient limitations other than $\mathrm{N}$ and does not consider biological limitations (i.e., weeds, insects, and diseases). To explore different water availability conditions (for the comparison of modified and current hybrids) two contrasting levels of total soil extractable water (EW) at sowing were simulated: 50\% (homogeneously distributed throughout the soil profile) and $100 \%$.

\section{RESULTS}

\section{Root Architecture and Water Uptake}

The modified hybrid had higher root density than the current hybrid below $100 \mathrm{~cm}$, being more marked in the drier site (Pilar) than in the wetter site (Pergamino): the mean increase in root length density below $100 \mathrm{~cm}$ was up to 0.7 in Pergamino and $1 \mathrm{~cm} \mathrm{~cm}^{-3}$ in Pilar (Fig. 1). There were no noticeable differences in root length density between the two initial extractable water levels (50 and $100 \% \mathrm{EW}_{\text {in }}$ ). Water uptake was different between both hybrids, and interacted with initial water availability.

The higher root density of the modified hybrid led to a significant increase of water uptake from deeper soil layers in all situations (Fig. 1). Conversely, the modified hybrid tended to show lower water uptake from upper layers, but only when $\mathrm{EW}_{\text {in }}$ was $100 \%$. However, the decrease in superficial water uptake of the modified hybrid was considerably less marked than the corresponding increase from deeper layers.

Simulated changes in root distribution increased total water uptake in most cases (i.e., the accumulated transpiration 
Pergamino
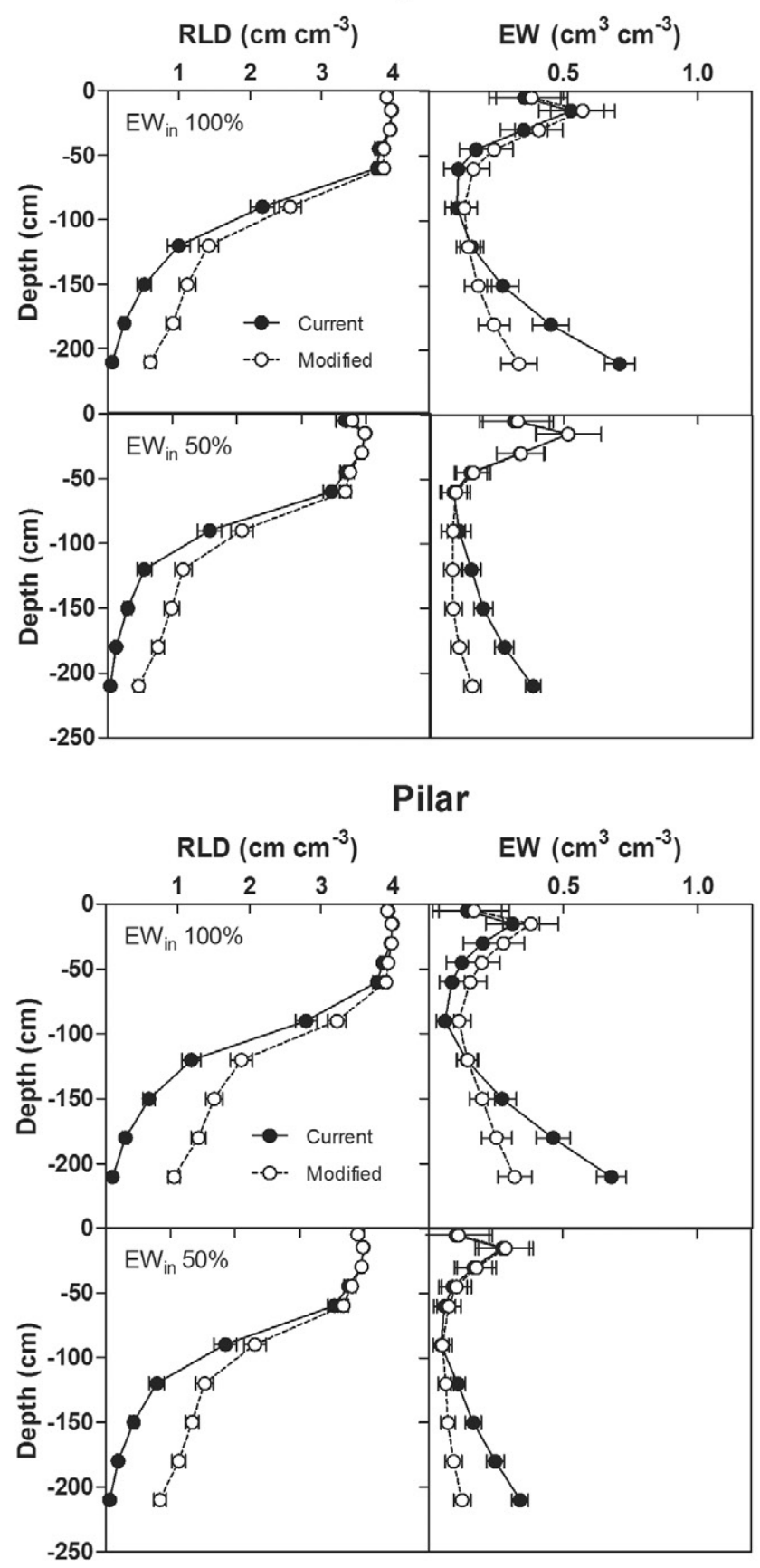

Fig. I. Root length distribution (RLD; $\mathrm{cm}$ of root per $\mathrm{cm}^{3}$ of soil) and extractable water (EW) at crop maturity as function of soil depth for the current (solid symbols) and modified hybrid (open symbols). Two different levels of initial extractable water (50 and $100 \%$ of total EW) were simulated for Pergamino and Pilar. Values correspond to the mean of simulations corresponding to the 193I to 2006 growing seasons. Horizontal bars show confidence interval (95\%).
Pergamino

Pilar

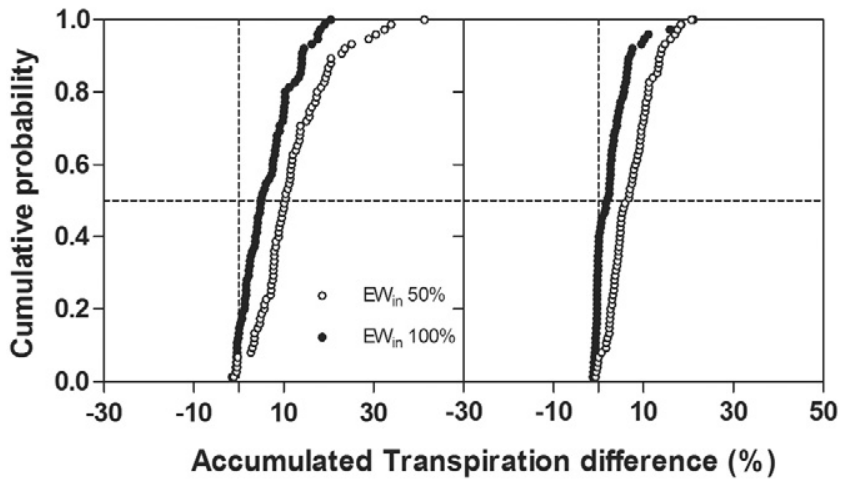

Fig. 2. Cumulative probability of the relative difference in accumulated transpiration (\%) between modified and current hybrid for $50 \%$ (open symbols) and $100 \%$ (solid symbols) initial soil extractable water $\left(\mathrm{EW}_{\text {in }}\right)$ and for Pergamino and Pilar. Each point corresponds to one cropping cycle from the 1931 to 2006 simulated period.

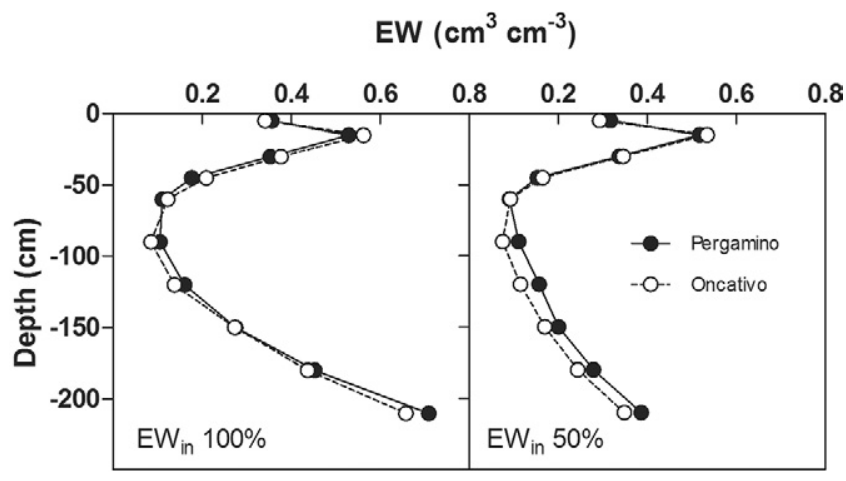

Fig. 3. Extractable water (EW) at maturity for the current hybrid in Pergamino (solid symbols) and Oncativo (open symbols) soil series using Pergamino climate records (for both soil series). Data simulated over 75 yr corresponding to the 1931 to 2006 growing seasons and for different conditions of initial soil extractable water $\left(\mathrm{EW}_{\text {in }}\right)$ : $50 \%$ of total EW and $100 \%$ of total EW.

throughout the cropping cycle; Fig. 2). Increases in water uptake, however, varied with sites and $\mathrm{EW}_{\text {in }}$ : uptake increases were higher for lower $\mathrm{EW}_{\text {in }}$. Furthermore, uptake increases were higher in Pergamino than in Pilar. The median increase of total water uptake for high $\mathrm{EW}_{\text {in }}$ was 6.5 and $2.9 \%$ for Pergamino and Pilar, respectively. For low $\mathrm{EW}_{\text {in }}$, the increase in water uptake was $12.0 \%$ for Pergamino and $7.2 \%$ for Pilar.

Differences in total transpiration between Pergamino and Pilar seemed to respond mainly to differences in soil characteristics. We hypothesized that the sandy Pilar soil (Oncativo series) may allow higher root length density and water uptake from deeper layers, even for the current hybrid. As a result, the current hybrid would leave a limited amount of water at depth to be reached by the modified hybrid. To

Table I. Mean yield of current and modified hybrid and mean yield differences (absolute and percentage). The differences were calculated as pair differences (modified-current) within each year. Mean calculations came from the $75 \mathrm{yr}$ for each site and extractable water (EW) combination.

\begin{tabular}{|c|c|c|c|c|}
\hline \multirow[b]{2}{*}{ Variable } & \multicolumn{2}{|c|}{ Pergamino } & \multicolumn{2}{|c|}{ Pilar } \\
\hline & $\mathrm{EW}_{\text {in }} 50 \% \dagger$ & $\mathrm{EW}_{\text {in }} 100 \%$ & $\mathrm{EW}_{\text {in }} 50 \%$ & $\mathrm{EW}_{\text {in }} 100 \%$ \\
\hline Mean yield of current hybrid, $\mathrm{kg} \mathrm{ha}^{-1}$ & 7331 & 10,404 & 7844 & 10,396 \\
\hline Mean yield of modified hybrid, $\mathrm{kg} \mathrm{ha}^{-1}$ & 8312 & 11,038 & 8304 & 10,656 \\
\hline Mean yield difference, $\mathrm{kg} \mathrm{ha}^{-1}$ & 921 & 456 & 429 & 192 \\
\hline Mean yield difference, $\%$ & 17.1 & 6.4 & 6.7 & 2.6 \\
\hline
\end{tabular}

$\dagger \mathrm{EW}_{\mathrm{in}}$, initial soil extractable water. 

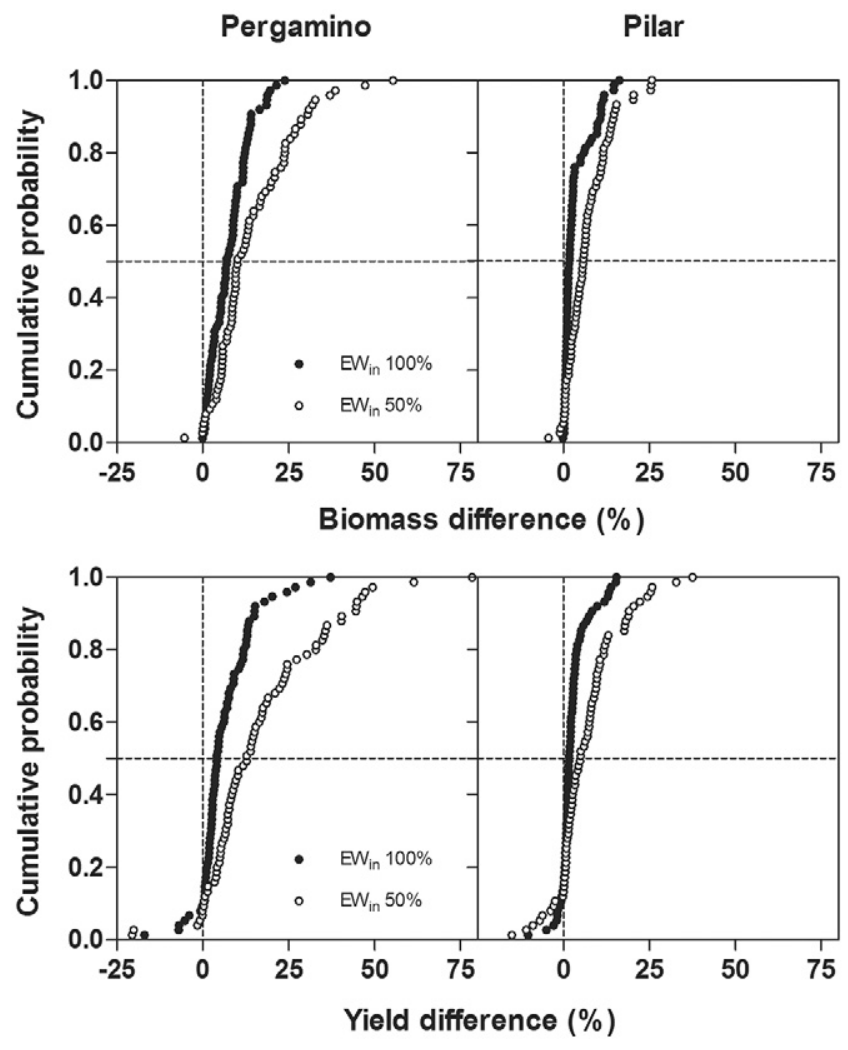

Fig. 4. Cumulative probability of the relative biomass (upper panels) and yield (lower panels) differences (\%) between modified and current hybrid for $50 \%$ (open symbols) and $100 \%$ (solid symbols) initial soil extractable water $\left(\mathrm{EW}_{\mathrm{in}}\right)$ and for Pergamino and Pilar. Each point corresponds to one cropping cycle from the 1931 to 2006 simulated period.

test this hypothesis, we performed simulations using the same climate record (Pergamino) for both soil profiles. The current hybrid tended to consume more water from deeper layers in the Pilar soil than in Pergamino, mainly for low EW in $_{\text {(Fig. }}$ 3). Consequently, the water remaining at deep soil layers (that could be absorbed by the modified hybrid) tended to be lower in Pilar than in Pergamino.

\section{Biomass and Yield Effects}

Given the strong link between transpiration and biomass production, in most simulations higher water uptake due to changes in root distribution led to increases in biomass production. These increases, however, varied between locations and with initial extractable water level (Fig. 4). In Pergamino, the mean increases in biomass production were $7.4 \%$ for $100 \mathrm{EW}_{\text {in }}$ and $14.5 \%$ for $50 \% \mathrm{EW}_{\text {in }}$, respectively; corresponding values were lower for Pilar (3.4 and $7.0 \%$ for 100 and $50 \% \mathrm{EW}_{\text {in }}$ ). These patterns agreed with simulated water uptake values. The maximum biomass increases reached almost $50 \%$ (for low $\mathrm{EW}_{\text {in }}$ in Pergamino) whereas in only one of 75 cropping cycles the relative biomass difference of the modified hybrid was slightly below 0 .

Grain yield advantages of the modified hybrid decreased as water availability increased. Mean simulated yields for the modified hybrid were higher than for the current one (Table 1). The differences between hybrids depended on the location and total water availability $\left(\mathrm{EW}_{\text {in }}+\right.$ rain $)($ Fig. 5). In Pergamino, mean yield differences were $456 \mathrm{~kg} \mathrm{ha}^{-1}(6.4 \%)$ and $921 \mathrm{~kg} \mathrm{ha}^{-1}(17.1 \%)$ for high and low $\mathrm{EW}_{\mathrm{in}}$, respectively. In Pilar, corresponding differences were $192 \mathrm{~kg} \mathrm{ha}^{-1}(2.6 \%)$ and $429 \mathrm{~kg} \mathrm{ha}^{-1}(6.7 \%)$ (Table 1 and Fig. 4). The highest yield increases were observed in years with low or medium water availability, depending on the site (Fig. 5). In years with higher water availability, yields tend to be similar for both hybrids. However, in Pergamino there were situations with considerable yield increases even under high water availability. The differences between sites may be tied to the lower potential yields of Pilar (maximum yield: $12,500 \mathrm{~kg} \mathrm{ha}^{-1}$ ) in relation to Pergamino (maximum yield: $14,052 \mathrm{~kg} \mathrm{ha}^{-1}$ ). Accordingly, in situations with high water availability other factors rather than water may limit yields in Pilar.

In a small proportion $(\approx 10 \%)$ of simulations, root architecture changes led to lower yields for the modified hybrid (Fig. 4). Because biomass production increased in the vast majority of situations (Fig. 4), the yield decrease was due to a reduction in harvest index (Fig. 6). In turn, this reduction was probably associated with water stress during crop stages when yield components (grain number and weight) are defined. Years in which root architecture modification led to yield reductions usually had precipitation in the lowest quintile, particularly in Pilar (Fig. 5).

Additionally, the distribution of precipitation in these years was uneven with higher rainfall during early crop stages (November) and lower rains later in the cycle (data not shown). Thus, abundant rain during vegetative stages allowed

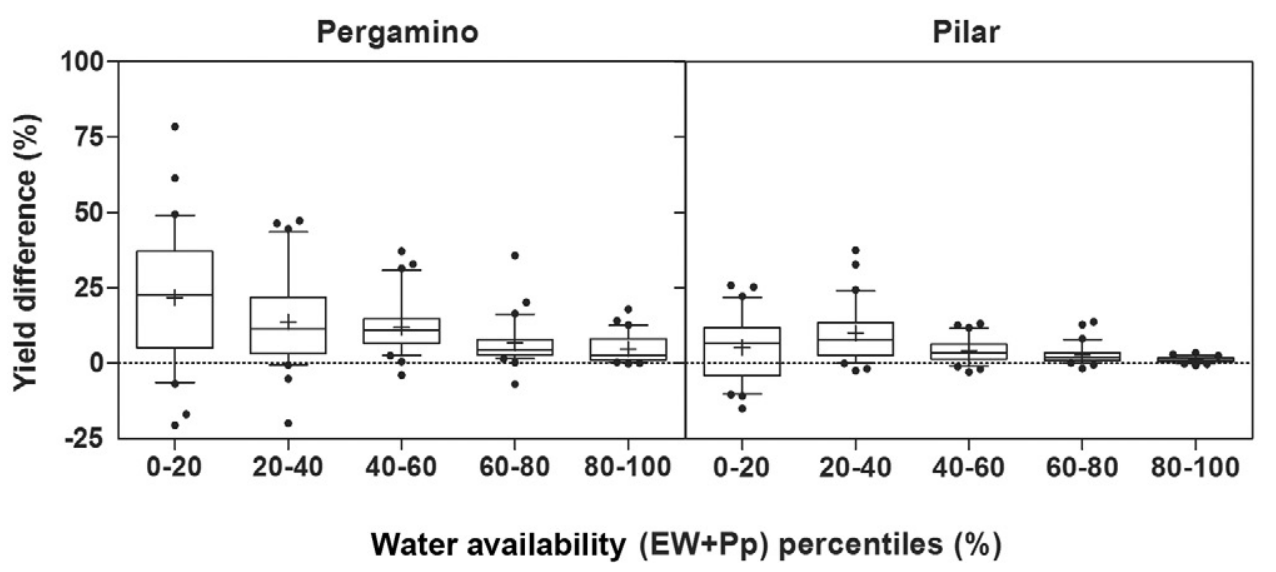

Fig. 5. Relative yield difference (\%) between modified and current hybrid for different categories corresponding to percentiles of water availability (being water availability $=$ total precipitations during crop cycle + extractable water at sowing). Data of each box plot correspond to 30 cropping cycles ( $20 \%$ of 75 cropping cycles and 2 initial soil extractable water $\left.\left[\mathrm{EW}_{\text {in }}\right]\right)$. 


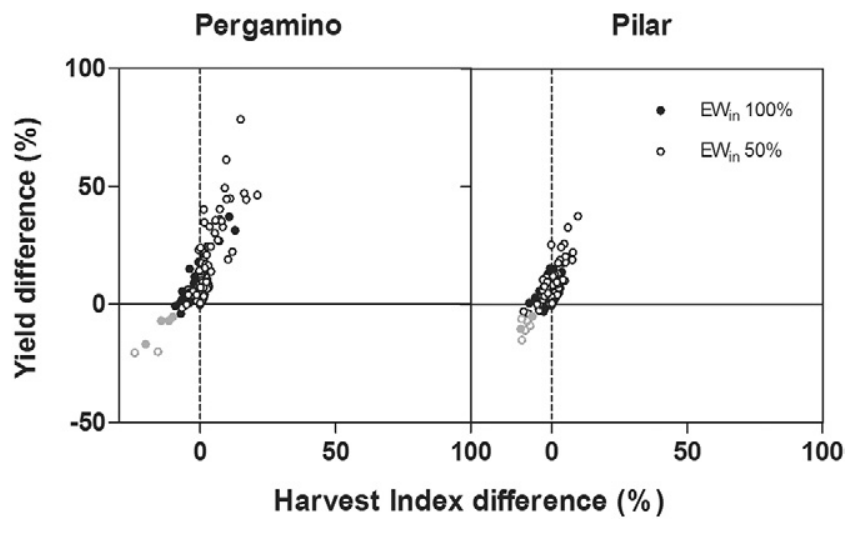

Fig. 6. Relative yield difference (\%) against relative harvest index difference (\%) between modified and current hybrid for $50 \%$ (open symbols) and $100 \%$ (solid symbols) initial soil extractable water $\left(E W_{\text {in }}\right)$ and for Pergamino and Pilar. Grey symbols indicate situations with negative yield difference lower than $-5 \%$. Each point corresponds to one cropping cycle from the I93I to 2006 simulated period.

roots of the modified hybrid to grow deeper and extract more water from deeper layers than the current hybrid. Early depletion of deeper soil water, together with low precipitation during the reproductive stages, led to higher water stress during critical yield generation periods, therefore reducing the harvest index for the modified hybrid. Indeed, for those situations where the modified hybrid had lower yield than current one, mean soil water content at the end of silking stage was 36.4 and $37.5 \%$ lower for the modified hybrid than for the current one in Pilar and Pergamino, respectively. Moreover, for those situations the mean value of the water stress index for growth (an output parameter from CERESMaize) of the beginning of grain filling period was 8.1 and $8.7 \%$ higher for the modified hybrid than for the current one in Pilar and Pergamino, respectively.

\section{DISCUSSION}

Important progress has been made recently in the genetic improvement of drought tolerance in maize. Given growing demand for food and energy, and increased concerns about increased climate variability and change, seed companies likely will continue to invest on enhancing drought tolerance during coming years (Tollefson, 2011). However, the physiological attributes that determine drought tolerance and, in particular, how these attributes interact with the environment still are insufficiently known. A higher root exploration of deep soil layers seems to be a promising mechanism to improve drought tolerance (Hall and Richards, 2013; Ludlow and Muchow, 1990; Richards, 2006; Singh et al., 2014; Tardieu, 2012). For this reason, we simulated a maize hybrid with higher density of deep roots and compared its response to water stress to that of an existing maize hybrid in two locations of the Argentine Pampas. In the next subsections we discuss: (i) the main findings derived from this study and (ii) their implications for maize production in rain-fed agricultural areas.

\section{Discussion of Main Findings}

Most of our results showed advantages for the modified hybrid: the enhanced root exploration of deep soil layers increased maize transpiration (i.e., water uptake), biomass production and, ultimately, grain yield. However, we also found strong interactions between root architecture and the environmental conditions in which crops are grown. We found that the performance of the modified hybrid during water stress depended on total water availability (soil water content at sowing plus rainfall during the cropping cycle) and sites. In the following paragraphs we examine these results in the context of the main findings from related studies.

The performance under water stress of the modified maize hybrid varied with total available water. We found higher advantages of the modified hybrid when soil water availability at sowing and/or rains during the cycle was scarce (Fig. 4 and 5). These results are consistent with other studies. For example, sorghum simulations made by Singh et al. (2014) suggested that yield increases due to modification of root attributes depended on the amount and distribution of rainfall, and on the water retention properties of the soil. Manschadi et al. (2006) showed higher yield differences between two wheat cultivars differing in soil root exploration with low initial soil water contents. Conversely, Lilley and Kirkegaard (2011) observed that increased wheat yield due to root changes were smaller in situations where the preceding land use resulted in a drier soil profile at sowing. Accordingly, the advantages of a modified root architecture depend not only on the total amount of water stored in the soil, but also on the distribution of that water throughout the profile. Hammer et al. (2009) suggested that soils with low or median amounts of stored water usually have little water at depth, thus limiting the advantages of a deeper root exploration.

There were not yield differences between the modified and current hybrids in years with high precipitation levels. This pattern coincides with experimental results by Chimenti et al. (2006) that demonstrated the absence of penalty of the modified attribute. However, the yields of the modified hybrid were lower than for the current one in about $10 \%$ of simulated situations. Such reductions responded to decreases in HI probably as a consequence of specific water stress during critical crop stages. The lower yields of the modified hybrid were particularly noticeable in low precipitation cropping cycles with most rain events concentrated in early vegetative crop stages. The higher root exploration of the modified hybrid lead to more water consumption during early crop stages leaving less water for critical reproductive stages. Similar results were observed for two wheat cultivars with difference in drought tolerance due to different soil root exploration (Manschadi et al., 2006) or with faster root descent and/or more effective water extraction in the subsoil (Lilley and Kirkegaard, 2011).

The performance under water stress of the modified maize hybrid also varied with site. We had originally hypothesized that changes in root architecture would have greatest advantages in the marginal semiarid area (Pilar). Surprisingly, the opposite pattern was found. These apparently counterintuitive results reinforce the notion that any assessment of the field-level advantages of new genotypes must, unavoidably, consider the complex interactions between modified attributes and the environment in which plants will be grown. Our simulations showed that higher drought tolerance linked to deeper root exploration would be more 
useful in situations where current maize hybrids leave unused water at depth (Fig. 1), as proposed by Hammer et al. (2009). We observed that the current hybrid left more water in deep layers in Pergamino than in Pilar-possibly due to soil water dynamics in the sandy Pilar soils that allow higher root exploration and water consumption at deep soil layers for the current hybrid-thus allowing higher yield increases due to root architecture changes $(+11.7$ and $+4.7 \%$ for Pergamino and Pilar, respectively).

In summary, our results reinforce the argument by Hall and Richards (2013) that genotype $\times$ environment interactions should be known to design effective selection strategies for genetic improvement. Additionally, we stress that these interactions have implications on the field-level advantages of a modified genotype and, therefore, should be known by the final users (i.e., farmers) to identify field situations in which the adoption of the genotype may enhance productivity. In the next subsection we discuss the main implications of our findings for agricultural production in rain-fed areas.

\section{Implications of the Main Findings}

A modified root architecture would make limited sense as a mechanism to improve drought tolerance when the amount of deep soil water is low (e.g., as a consequence of consumption by a previous crop or weeds, or low rainfall during fallow) (Hammer et al., 2009; Lilley and Kirkegaard, 2011). Additionally, the higher extraction by modified hybrids could leave lower soil water levels for the subsequent crop (unless fallow rains are sufficient to recharge the soil fully). This reinforces the importance of understanding the interactions between the attribute conferring drought tolerance and the environmental conditions, including preceding and subsequent crops.

The decision to use a "drought tolerant hybrid" (with higher root exploration) should be taken not only in response to predictions of low rain (e.g., from seasonal climate forecasts), but also after monitoring the level and distribution of soil water content at sowing. While current climate forecasts still have considerable uncertainty, soil water and its distribution can be easily measured or estimated before sowing. Moreover, the higher yield response found in situations with low $\mathrm{EW}_{\text {in }}$ demonstrates that changes in root architecture not only would enhance yield in low precipitation seasons, but also would reduce the risks of sowing on soils with dry upper layers but with available water at depth that is not reached by actual hybrids.

The absence of yield reductions under favorable conditions of water availability would foster the adoption of droughttolerant related technologies; the farmers would not show regret by having chosen a drought-tolerant hybrid (likely to be more expensive) even if rainfall during the cycle turns out normal or above normal. However, the yield reductions observed in seasons with low and unevenly distributed rains could discourage the use of maize hybrid with higher density of deep roots. Although this is not a frequent rainfall pattern in the Pampas - note that only $10 \%$ of simulated situations led to yield reductions - this finding should be carefully considered in agricultural regions with terminal droughts.

Our simulations assume that root growth is not limited by any physical or chemical factors. Nevertheless, it would be necessary to assess the performance of simulated hybrids in soils with different limitations to root growth. Some soils in the Pampas present impedances to normal root growth (e.g., thaptic horizons or, in extreme cases, petrocalcic horizons). Under such conditions, the potential advantages of changes in root architecture may disappear. Additionally, the CERESMaize model assumes that roots are uniformly distributed in the horizontal dimension. However, Argiudolls and Hapluderts soils are known for their swelling and cracking characteristics that may result in root clumping (i.e., nonuniform root distribution on the horizontal plane). This characteristic also restricts the ability of roots to extract water and nutrients due to limited proliferation into the surrounding soil (Dardanelli et al., 2004; Passioura, 1983, 1996).

The abandonment of ecologically-sound crop rotations and the increasing trend toward soybean monoculture in the Argentine Pampas is raising concerns about the sustainability of production systems (Manuel-Navarrete et al., 2009). In this context, maize offers an attractive diversification alternative with potential benefits for several soil attributes. However, agriculture in the Pampas is almost entirely rain fed, and maize is extremely sensitive to water deficits. Our results showed that higher root exploration of deep soil layers may enhance drought tolerance in maize. The availability of maize genotypes able to maintain production levels under water stress would provide competitive advantages to this crop under drier scenarios of future climate in the Pampas. However, our study showed that the potential yield advantages of this attribute are unevenly expressed throughout different agroecological conditions, and that the highest benefits of higher density of deep roots do not necessarily appear in near marginal areas.

\section{CONCLUSION}

This work showed that a higher root exploration of deep soil layers may increase maize transpiration, biomass production and grain yield under low water availability. Consequently, hybrids with higher root density on deep soil layers may enhance maize tolerance to water stress in rain-fed agricultural systems. These results suggest that root architecture may be considered as a promising attribute to enhance drought tolerance in breeding programs. However, we showed that strong interactions between root modifications and the field conditions in which plants are grown affect the likely field-level yield advantages of drought-tolerant genotypes. We highlight the need for assessing attributes tied to drought tolerance in the context of agroecological conditions of the target production systems. This assessment will allow to identify which droughttolerance mechanisms might prove effective under different water-stress conditions.

\section{ACKNOWLEDGMENTS}

This research was supported by the U.S. National Science Foundation, grants 0709681 and 1211613 (Dynamics of Coupled Natural and Human Systems) and 1049109 (Decadal Regional Climate Prediction using Earth System Models) and by the IAI, grant 2031-addendum (Collaborative Research Network 2). R. Carretero and F. Bert are supported by CONICET (Consejo Nacional de Investigaciones Científicas y Técnicas) of Argentina. Early ideas for this paper were discussed with Dr. Carlos D. Messina. Thanks to the anonymous reviewers for this manuscript. 


\section{REFERENCES}

Berbery, E.H., M.E. Doyle, and V. Barros. 2006. Tendencias regionales en la precipitación. In: V. Barros, R. Clarke, and P. Silva Días, editors, El cambio climático en la Cuenca del Plata. CONICET, Buenos Aires, Argentina. p. 67-92.

Bert, F.B., E.H. Satorre, F. Ruiz Toranzo, and G.P. Podestá. 2006. Climatic information and decision-making in maize crop production systems of Argentinean Pampas. Agric. Syst. 88:180-204. doi:10.1016/j. agsy.2005.03.007

Blum, A. 2005. Drought resistance, water-use efficiency, and yield potentialAre they compatible, dissonant, or mutually exclusive? Aust. J. Agric. Res. 56:1159-1168. doi:http://dx.doi.org/10.1071/AR05069.

Blum, A. 2009. Effective use of water (EUW) and not water-use efficiency (WUE) is the target of crop yield improvement under drought stress. Field Crops Res. 112:119-123. doi:http://dx.doi.org/10.1016/j.fcr.2009.03.009.

Boulanger, J.-P., J. Leloup, O. Penalba, M. Rusticucci, F. Lafon, and W. Vargas. 2005. Observed precipitation in the Paraná-Plata hydrological basin: Long-term trends, extreme conditions and ENSO teleconnections. Clim. Dyn. 24:393-413. doi:10.1007/s00382-004-0514-x

Boulanger, J.-P., F. Martínez, and E.C. Segura. 2007. Projection of future climate change conditions using IPCC simulations, neural networks and Bayesian statistics. Part 2: Precipitation mean state and seasonal cycle in South America. Clim. Dyn. 28:255-271. doi:10.1007/ s00382-006-0182-0

Bruce, W.B., G.O. Edmeades, and T.C. Barker. 2002. Molecular and physiological approaches to maize improvement for drought tolerance. J. Exp. Bot. 53:13-25. doi:10.1093/jexbot/53.366.13

Calviño, P.A., and J.P. Monzón. 2009. Farming systems of Argentina: Yield constraints and risk management. Crop physiology: Applications for genetic improvement and agronomy. Elsevier Academic Press, San Diego, CA.

Campos, H., M. Cooper, J.E. Habben, G.O. Edmeades, and J.R. Schussler. 2004. Improving drought tolerance in maize: A view from industry: Linking functional genomics with physiology for global change research. Field Crops Res. 90:19-34. doi:10.1016/j.fcr.2004.07.003

Chimenti, C.A., M. Marcantonio, and A.J. Hall. 2006. Divergent selection for osmotic adjustment results in improved drought tolerance in maize (Zea mays L.) in both early growth and flowering phases. Field Crops Res. 95:305-315. doi:http://dx.doi.org/10.1016/j.fcr.2005.04.003.

Condon, A.G., R.A. Richards, G.J. Rebetzke, and G.D. Farquhar. 2002. Improving intrinsic water-use efficiency and crop yield. Crop Sci. 42:122-131. doi:10.2135/cropsci2002.0122

Dardanelli, J.L., J.T. Ritchie, M. Calmon, J.M. Andriani, and D.J. Collino. 2004. An empirical model for root water uptake. Field Crops Res. 87:5971. doi:http://dx.doi.org/10.1016/j.fcr.2003.09.008.

Delvenne, P., F. Vasen, and A.M. Vara. 2013. The "soy-ization" of Argentina: The dynamics of the "globalized" privatization regime in a peripheral context. Technol. Soc. 35:153-162. doi:10.1016/j.techsoc.2013.01.005

Ferreyra, A., G. Podestá, C. Messina, D. Letson, J. Dardanelli, E. Guevara et al. 2001. A linked-modeling framework to estimate maize production risk associated with ENSO-related climate variability in Argentina. Agric. For. Meteorol. 107:177-192. doi:10.1016/S0168-1923(00)00240-9

Giuliani, S., M.C. Sanguineti, R. Tuberosa, M. Bellotti, S. Salvi, and P. Landi. 2005. Root-ABA1, a major constitutive QTL, affects maize root architecture and leaf ABA concentration at different water regimes. J. Exp. Bot. 56:3061-3070. doi:10.1093/jxb/eri303

Goddard, L., S.J. Mason, S.E. Zebiak, C.F. Ropelewski, R. Basher, and M.A. Cane. 2001. Current approaches to seasonal-to-interannual climate predictions. Int. J. Climatol. 21:1111-1152. doi:10.1002/joc.636

Guevara, E., S. Meira, M. Maturano, and G. Coco. 1999. Maize simulation for different environments in Argentina. In: M. Donatelli, C. Stockle, F. Villalobos, and J.M. Villar Mir, editors, International Symposium: Modelling Cropping Systems. European Soc. of Agron., Univ. of Lleida, Catalonia, Spain. 21-23 June 1999. European Soc. of Agron., Montpellier, France. p. 193-194.

Hall, A.J., C.M. Rebella, C.M. Ghersa, and J.-P. Culot. 1992. Field crops systems of the Pampas. In: C.J. Pearson, editor, Field crops systems: Ecosystems of the world. Elsevier, Amsterdam. p. 413-449.

Hall, A.J., and R.A. Richards. 2013. Prognosis for genetic improvement of yield potential and water-limited yield of major grain crops. Field Crops Res. 143:18-33. doi:http://dx.doi.org/10.1016/j.fcr.2012.05.014.
Hammer, G.L., S. Chapman, E. van Oosterom, and D.W. Podlich. 2005. Trait physiology and crop modelling as a framework to link phenotypic complexity to underlying genetic systems. Aust. J. Agric. Res. 56:947960. doi:http://dx.doi.org/10.1071/AR05157.

Hammer, G.L., Z. Dong, G. McLean, A. Doherty, C. Messina, J. Schussler et al. 2009. Can changes in canopy and/or root system architecture explain historical maize yield trends in the U.S. Corn Belt? Crop Sci. 49:299312. doi:10.2135/cropsci2008.03.0152

Hoogenboom, G., P.W. Wilkens, P.K. Thornton, J.W. Jones, L.A. Hunt, and D.T. Imamura. 1999. Decision support system for agrotechnology transfer v3.5. In: G. Hoogenboom, P.W. Wilkens, and G.Y. Tsuji, editors, DSSAT version 3. Vol. 4. Univ. of Hawaii, Honolulu. p. 1-36.

Jones, C.A., W.L. Bland, J.T. Ritchie, and J.R. Williams. 1991. Simulation of root growth. In: J. Hanks and J.T. Ritchie, editors, Modeling plant and soil systems. ASA, CSSA, and SSSA, Madison, WI. p. 91-123.

Jones, C.A., and J.R. Kiniry, editors. 1986. CERES-Maize: A simulation model of maize growth and development. Texas A\&M Univ. Press, College Station.

Jones, J.W., and B. Zur. 1984. Simulation of possible adaptive mechanisms in crops subjected to water stress. Irrig. Sci. 5:251-264. doi:10.1007/BF00258178

Jordan, W.R., W.A. Dugas, Jr., and P.J. Shouse. 1983. Strategies for crop improvement for drought-prone regions. Agric. Water Manage. 7:281299. doi:http://dx.doi.org/10.1016/0378-3774(83)90090-2.

Kato, Y., J. Abe, A. Kamoshita, and J. Yamagishi. 2006. Genotypic variation in root growth angle in rice (Oryza sativa $\mathrm{L}$.) and its association with deep root development in upland fields with different water regimes. Plant Soil 287:117-129. doi:10.1007/s11104-006-9008-4

Leguizamón, A. 2014. Modifying Argentina: GM soy and socio-environmental change. Geoforum 53:149-160. doi:10.1016/j.geoforum.2013.04.001

Lilley, J.M., and J.A. Kirkegaard. 2011. Benefits of increased soil exploration by wheat roots. Field Crops Res. 122:118-130. doi:http://dx.doi. org/10.1016/j.fcr.2011.03.010.

Lorens, G.F., J.M. Bennett, and L.B. Loggale. 1987a. Differences in drought resistance between two corn hybrids. I. Water relations and root length density. Agron. J.79:802-807. doi:10.2134/agronj1987.00021962007900050009x

Lorens, G.F., J.M. Bennett, and L.B. Loggale. 1987b. Differences in drought resistance between two corn hybrids. II. Component analysis and growth rates. Agron.J.79:808-813. doi:10.2134/agronj1987.00021962007900050010x.

Ludlow, M.M., and R.C. Muchow. 1990. A critical evaluation of traits for improving crop yields in water-limited environments. In: N.C. Brady, editor, Advances in agronomy. Academic Press, San Diego, CA. p. 107-153.

Manschadi, A., G. Hammer, J. Christopher, and P. deVoil. 2008. Genotypic variation in seedling root architectural traits and implications for drought adaptation in wheat (Triticum aestivum L.). Plant Soil 303:115129. doi:10.1007/s11104-007-9492-1

Manschadi, A.M., J. Christopher, P. deVoil, and G.L. Hammer. 2006. The role of root architectural traits in adaptation of wheat to water-limited environments. Funct. Plant Biol. 33:823-837. doi:http://dx.doi. org/10.1071/FP06055.

Manuel-Navarrete, D., G. Gallopín, M. Blanco, M. Díaz-Zorita, D. Ferraro, H. Herzer et al. 2009. Multi-causal and integrated assessment of sustainability: The case of agriculturization in the Argentine Pampas. Environ. Dev. Sustain. 11:621-638. doi:10.1007/s10668-007-9133-0

McKenzie, B.M., A.G. Bengough, P.D. Hallett, W.T.B. Thomas, B. Forster, and J.W. McNicol. 2009. Deep rooting and drought screening of cereal crops: A novel field-based method and its application. Field Crops Res. 112:165-171. doi:http://dx.doi.org/10.1016/j.fcr.2009.02.012.

Mercau, J.L., E.H. Satorre, M.E. Otaegui, G.A. Maddoni, J. Cárcova, R. Ruiz et al. 2001. Evaluación a campo del comportamiento del modelo Ceres en cultivos de maíz del norte de la provincia de Buenos Aires. In: Asoc. de Ingenieros Agronomos del Norte de la Provincia de Buenos Aires, editor, Proceedings of VII Congreso Nacional de Maíz, Pergamino, Argentina. 1-7 Nov. 2001. Asoc. de Ingenieros Agronomos del Norte de la Provincia de Buenos Aires, Pergamino, Buenos Aires, Argentina.

Minetti, J.L., W. Vargas, A.G. Poblete, L.R. Acuña, and G. Casagrande. 2003. Non-linear trends and low frequency oscillations in annual precipitation over Argentina and Chile, 1931-1999. Atmosfera 16:119-135.

Morgan, J., and A. Condon. 1986. Water use, grain yield, and osmoregulation in wheat. Funct. Plant Biol. 13:523-532. doi:http://dx.doi.org/10.1071/ PP9860523.

Nagore, M.L., L. Echarte, F.H. Andrade, and A. Della Maggiora. 2014. Crop evapotranspiration in Argentinean maize hybrids released in different decades. Field Crops Res. 155:23-29. doi:http://dx.doi.org/10.1016/j.fcr.2013.09.026. 
Paruelo, J.M., J.P. Guerschman, and S.R. Verón. 2005. Expansión agrícola y cambios en el uso del suelo. Cienc. Hoy 15:14-23.

Passioura, J.B. 1983. Roots and drought resistance. In: J.F. Stone and W.O. Willis, editors, Plant production and management under drought conditions. Elsevier, Amsterdam. p. 265-280.

Passioura, J.B. 1996. Drought and drought tolerance. Plant Growth Regul. 20:79-83. doi:10.1007/BF00024003

Passioura, J.B. 2006. Increasing crop productivity when water is scarce-From breeding to field management. Agric. Water Manage. 80:176-196. doi:http://dx.doi.org/10.1016/j.agwat.2005.07.012.

Passioura, J.B. 2012. Phenotyping for drought tolerance in grain crops: When is it useful to breeders? Funct. Plant Biol. 39:851-859. doi:http://dx.doi. org/10.1071/FP12079.

Podestá, G., F. Bert, B. Rajagopalan, S. Apipattanavis, C. Laciana, E. Weber et al. 2009. Decadal climate variability in the Argentine Pampas: Regional impacts of plausible climate scenarios on agricultural systems. Clim. Res. 40:199-210. doi:10.3354/cr00807

Podestá, G.P., C.D. Messina, M.O. Grondona, and G.O. Magrín. 1999. Associations between grain crop yields in central-eastern Argentina and El Niño-Southern Oscillation. J. Appl. Meteorol. 38:1488-1498. doi:10.1175/1520-0450(1999)0382.0.CO;2

Rebetzke, G.J., A.G. Condon, R.A. Richards, and G.D. Farquhar. 2002. Selection for reduced carbon isotope discrimination increases aerial biomass and grain yield of rainfed bread wheat. Crop Sci. 42:739-745. doi:10.2135/cropsci2002.0739

Reboratti, C.E. 2010. Un mar de soja: La nueva agricultura en Argentina y sus consecuencias. Revista de Geografía Norte Grande 45:63-76.

Richards, R.A. 2006. Physiological traits used in the breeding of new cultivars for water-scarce environments. Agric. Water Manage. 80:197-211. doi:http://dx.doi.org/10.1016/j.agwat.2005.07.013.

Robertson, M.J., S. Fukai, G.L. Hammer and M.M. Ludlow. 1993. Modelling root growth of grain sorghum using the CERES approach. Field Crops Res. 33:113-130. doi:http://dx.doi.org/10.1016/0378-4290(93)90097-7.

Ropelewski,C.F.and M.S.Halpert. 1987.Globaland regionalscale precipitation patternsassociated with theElNiño/Southern Oscillation. Mon. Weather Rev. 115:1606-1626. doi:10.1175/1520-0493(1987)1152.0.CO;2.
Ropelewski, C.F., and S. Halpert. 1989. Precipitation patterns associated with the high index phase of the Southern Oscillation. J. Clim. 2:268-284. doi:10.1175/1520-0442(1989)0022.0.CO;2

Rusticucci, M., and O. Penalba.2000. Interdecadal changes in the precipitation seasonal cycle over Southern South America and their relationship with surface temperature. Clim. Res. 16:1-15. doi:10.3354/cr016001

Salih, A.A., I.A. Ali, A. Lux, M. Luxová, Y. Cohen, Y. Sugimoto et al. 1999. Rooting, water uptake, and xylem structure adaptation to drought of two sorghum cultivars. Crop Sci. 39:168-173. doi:10.2135/cropsci1999.0011 183X003900010027x

Sinclair, T.R., and R.C. Muchow. 2001. System analysis of plant traits to increase grain yield on limited water supplies. Agron. J. 93:263-270. doi:10.2134/agronj2001.932263x

Singh, P., S. Nedumaran, P.C.S. Traore, K.J. Boote, H.F.W. Rattunde, P.V.V. Prasad et al. 2014. Quantifying potential benefits of drought and heat tolerance in rainy season sorghum for adapting to climate change. Agr. Forest Meteorol. 185:37-48. doi:http://dx.doi.org/10.1016/j. agrformet.2013.10.012.

Singh, V., E. Oosterom, D. Jordan, C. Messina, M. Cooper, and G. Hammer. 2010. Morphological and architectural development of root systems in sorghum and maize. Plant Soil 333:287-299. doi:10.1007/ s11104-010-0343-0

Skansi, M.M., S.E. Núñez, G.P. Podestá, and N. Garay. 2009. La sequía del año 2008 en la región húmeda argentina descripta a través del Indice de Precipitación Estandarizado. CONGREMET 2009. Centro Argentino de Meteorólogos, Buenos Aires, Argentina.

Tardieu, F. 2012. Any trait or trait-related allele can confer drought tolerance: Just design the right drought scenario. J. Exp. Bot. 63:25-31. doi:10.1093/jxb/err269

Tollefson, J. 2011. Drought-tolerant maize gets US debut. Nature (London) 469:144. doi:10.1038/469144a

Wan, C., W. Xu, R. Sosebee, S. Machado, and T. Archer. 2000. Hydraulic lift in drought-tolerant and-susceptible maize hybrids. Plant Soil 219:117126. doi:10.1023/A:1004740511326 